\section{Research Square \\ Preprints are preliminary reports that have not undergone peer review. \\ They should not be considered conclusive, used to inform clinical practice, or referenced by the media as validated information.}

\title{
The Effect of Educational Intervention on Efficacy of 1\% Permethrin Shampoo and 4\% Dimeticone Lotion to Treat Head Lice Infestation Using Propensity Score Matching (PSM)
}

\author{
Eslam Moradi Asl ( $\nabla$ moradiasl83@yahoo.com) \\ Ardabil University of Medical Sciences \\ Abedin Saghafipour \\ Qom University of Medical Sciences \\ Amir Hamta \\ Qom University of Medical Sciences \\ Zahra Taheri-Kharameh \\ Qom University of Medical Sciences \\ Malek Abazari \\ Ardabil University of Medical Sciences \\ Shabnam Asghari \\ Tehran University of Medical Sciences
}

Research Article

Keywords: Head lice, Infestation, Pediculicides, Education,Iran

Posted Date: June 16th, 2021

DOI: https://doi.org/10.21203/rs.3.rs-605543/v1

License: (c) (1) This work is licensed under a Creative Commons Attribution 4.0 International License. Read Full License 


\section{Abstract \\ Background}

Head lice are a main public health problem and the most important human ectoparasites and the use of pediculicides is the most common way to control it. One of the possible causes of treatment failure is the lack of improper application of pediculicide. The aim of this study was to assess the effect of education on efficacy of $1 \%$ permethrin or $4 \%$ dimeticone lotion to treat head lice infestation.

\section{Methods}

This quasi-experimental study was performed on 100 people infected with head lice in comprehensive urban health centers of Ardabil (intervention group) and 400 people of East Azerbaijan and West Azerbaijan (control group) provinces from April to March 2019. The data collection tool included demographic questionnaire and examination evidence recording sheet in terms of presence of hits or adult lice.

\section{Results}

The outcome of treatment included elimination of head lice infestation on days 7, and in the case of recurrence, it was considered on days 14 and 30 after treatment. Data were analyzed using R software and Generalized Estimating Equation method. GEE analysis showed there is significant difference in evaluating head lice over time.

\section{Conclusion}

Participants who received the training intervention ( $\mathrm{OR}=3.29 ; \mathrm{Cl} 95 \%: 2.21-4.88$ ) were more likely to have a successful treatment than control group. In the case of providing proper training on the use of pediculicides and observing hygiene tips to patients with pediculosis, could help to successful treatment of pediculosis.

\section{Background}

head lice (Pediculus humanus capitis) belong to the Phylum Arthropoda, Class Insecta, Order Phthiraptera, and it is considered as compulsive ectoparasitis of mammals, including humans and it is transmitted mainly by direct contact with the hair of an infected person [1]. Pediculosis, which results from head lice infestation in humans, is common in all parts of the world, but is more prevalent in places with high population densities [2]. Its prevalence in developing countries has been reported at $40 \%$. The prevalence of head lice infestation in different regions of Iran is relatively high [3]. Head lice infestation can lead to feelings of inferiority, psychological distress, depression, insomnia, academic failure, stigma, secondary infestations, hair loss, and allergies [4]. One of the ways to prevent head lice is to follow personal hygiene, take regular baths and avoid using other people's personal belongings [5]. Many therapies have been studies and evaluated for head lice treatment in the world and in Iran [6]. At the present time, in Iranian health centers, two products of $1 \%$ Permethrin or $4 \%$ dimeticone are routinely used to treat head lice. According to results of a study, the use of two anti-lice insecticides, permethrin\% 1 shampoo and dimethicone $4 \%$ lotion, which are commonly used in Iran based on the recommendation of the Center for Management of Infectious Diseases, had a relatively equal effect on the treatment of people with head lice infestation [6]. Pediculicides do not completely kill nits, and a number of nits hatch after the incubation period, mature into adult head lice and the cycle begins again [7]. Numerous factors such as frequent infestations, different densities of infestation in different cities, parental education level, socio-economic level, probability of drug resistance and differences in the method and quality of education to patients, etc. can be the cause of its recurrence [8-9]. Pediculicides may be more effective in treating pediculosis if used properly. Due to the high prevalence of head lice in recent years in in the northwest of the Iran such as Ardabil province (with a population of about one million and four hundred thousand people) [10] and the increasing trend in the use of anti-insect solutions and imposing a heavy cost on the patient care system, this study aims to evaluate the effect of educational intervention on the efficacy of two common anti-lice insecticides in Iran, namely $1 \%$ permethrin shampoo and $4 \%$ dimethicone lotion in the treatment of head lice infestation using statistical method of propensity score matching (PSM).

\section{Materials And Methods Design and participants}

In this quasi-experimental study, the efficacy of common anti-insect solutions used in the treatment of head lice (Permethrin $1 \%$ shampoo or $4 \%$ dimethicone lotion) prescribed routinely by Ministry of Health, was done on 100 subjects with head lice infestation in comprehensive urban health centers of Ardabil province (intervention group) and 400 subjects of East Azerbaijan and West Azerbaijan (control group) provinces from April to March 2019. The two provinces of Azerbaijan and Ardabil, from which case and control samples have been selected, are completely similar in terms of culture, customs, lifestyle, economic and social status. The number of subjects for each treatment method in all urban and rural areas was equal, so the equal distribution of socio-economic confounding factors in response to treatment was ensured. The most important confounding factor in therapeutic effect was the possibility of re-infestation of people who are around the infected person after the start of the trial and treatment, which could potentially appear in the role of reducing the therapeutic effect. To overcome it, all home contact cases, without considering that infestation was diagnosable or non-diagnosable, were treated simultaneously. 
In the intervention group, before prescribing the shampoos, the correct method of using these anti-lice shampoos was practically taught by the medical entomology experts. Subjects in intervention group received 30 minutes of training. The training consisted of the head lice and ways of transmitting the disease (10 minutes), the pediculicide such as $1 \%$ permethrin and $4 \%$ dimeticone lotion (10 minutes) and how to use them properly in the treatment of head lice (10 minutes) using role-playing method. However, the control group in both East and West Azerbaijan provinces were treated routinely. Each treatment included using $1 \%$ permethrin shampoo twice or $4 \%$ dimethicone lotion according to the instructions. The outcome of the treatment included removal of adult human head lice, nymphs, and nits in confirmed human cases at 14 and 30 days after starting treatments were considered. Data were collected through a researcher-made questionnaire and through observation and examination.

\section{Data analysis}

Unlike clinical trial studies, in observational studies subjects are not assigned at random to two groups and estimation the effect of treatment would have been challenging [11]. Random assignment is done in order to distribution of covariate in both group become similar and in this sense groups are comparable. The propensity score matching (PSM) is a powerful method, in situation that random assignment is absent, for balancing numerous observed covariates [12]. In this study by using PSM confounding variables and treatment selection were controlled. Based on PSM multidimensional pretreatment confounder covariates transformed to one-dimensional variable and as a result similarity in distribution of covariates in both groups is happened [13]. Next the propensity score was calculated, and matching was done. All 100 patients in case group were matched by applying by 1:2 PSM employing nearest neighbor method. Prognostic score based balanced was used in order to evaluating bias reduction in PSM. The most popular matric balance measure prognostic score, standardized mean difference (SMD), has been used. This statistics is used to examine the balance of confounders between intervention and control group [14]. SMD greater than 0.1 shows the significant dissimilarity [15]. The strength of SMD is sample size does not have influence on it [16]. Figure 1 shows study follow diagram. In the next step matched data, since head lice infestation each individual was investigated three times and measurements are dependent, for considering dependency, generalized Estimating Equations (GEE) was applied [17]. All statistical analysis were done using R version 3.6.3 software.

\section{Result}

In total, 100 subjects in intervention group and 400 subjects in control group completed the study. The result showed before applying PSM the mean age of intervention and control group was significantly different. The age of individual in intervention group was $16.18 \pm 12.61$ and in control group it was $13.09 \pm 10.21(P<0.05)$ and SMD for age of participants 0.27 was obtained. Conspicuously SMD showed the distribution of age is too different to compare, while after applying PSM the age of individuals in both group was not statistically significant any more (16.18 \pm 12.61 vs $16.34 \pm 12.52$ in intervention and control groups respectively, P-value=0.92). The comparison of characteristics of both group before and after applying PSM are presented in table1. This table reveals after matching analogy between variables' distribution is accomplished.

GEE analysis showed there is significant difference in evaluating head lice over time (Table 1).

Table1. Individual characteristics before and after matching

\begin{tabular}{|c|c|c|c|c|c|c|c|c|}
\hline \multirow[t]{2}{*}{ variables } & \multicolumn{4}{|c|}{ Before PSM count (Percent) } & \multicolumn{4}{|c|}{ After PSM count (Percent) } \\
\hline & $\begin{array}{l}\text { Control group, } \\
n=400\end{array}$ & $\begin{array}{l}\text { Treatment Group, } \\
n=100\end{array}$ & SMD & $P$ & $\begin{array}{l}\text { Control group, } \\
n=200\end{array}$ & $\begin{array}{l}\text { Treatment Group, } \\
n=100\end{array}$ & SMD & $P$ \\
\hline \multicolumn{9}{|l|}{ Sex } \\
\hline 1 & 105 ( 26.2) & $25(25.0)$ & 0.029 & 0.899 & $51(25.5)$ & $25(25.0)$ & 0.012 & $>0.999$ \\
\hline 2 & $295(73.8)$ & $75(75.0)$ & & & 149 ( 74.5$)$ & $75(75.0)$ & & \\
\hline \multicolumn{9}{|l|}{ Size of hear } \\
\hline 1 & $127(31.8)$ & $28(28.0)$ & 0.109 & 0.617 & $67(33.5)$ & $28(28.0)$ & 0.121 & 0.490 \\
\hline 2 & $167(41.8)$ & $41(41.0)$ & & & $69(34.5)$ & $41(41.0)$ & & \\
\hline 3 & $106(26.5)$ & $31(31.0)$ & & & $64(32.0)$ & $31(31.0)$ & & \\
\hline \multicolumn{9}{|l|}{ Infestation rate } \\
\hline 1 & $144(36.0)$ & $30(30.0)$ & 0.207 & 0.161 & $62(31.0)$ & $30(30.0)$ & 0.071 & 0.844 \\
\hline 2 & $188(47.0)$ & $45(45.0)$ & & & $94(47.0)$ & $45(45.0)$ & & \\
\hline 3 & $68(17.0)$ & $25(25.0)$ & & & $44(22.0)$ & $25(25.0)$ & & \\
\hline \multicolumn{9}{|l|}{ Type of treatment } \\
\hline $\begin{array}{l}1 \% \text { permethrin } \\
\text { shampoo }\end{array}$ & $206(51.5)$ & $50(50.0)$ & 0.030 & 0.876 & $92(46.0)$ & $50(50.0)$ & 0.080 & 0.595 \\
\hline $4 \%$ dimeticone lotion & $194(48.5)$ & $50(50.0)$ & & & $108(54.0)$ & $50(50.0)$ & & \\
\hline
\end{tabular}

Participants who received the training intervention ( $\mathrm{OR}=3.29, \mathrm{Cl} 95 \%: 2.21-4.88)$ were more likely to have a successful treatment $(\mathrm{Table} 2)$.

Table 2. Head lice treatment results with $1 \%$ permethrin and $4 \%$ dimeticone lotion in intervention and control group 


\begin{tabular}{|c|c|c|c|c|c|c|c|c|c|c|c|}
\hline \multirow{4}{*}{$\begin{array}{l}\text { Efficacy } \\
\text { of } \\
\text { treatment }\end{array}$} & \multicolumn{6}{|c|}{$1 \%$ permethrin shampoo } & \multicolumn{5}{|c|}{$4 \%$ dimeticone lotion } \\
\hline & \multicolumn{2}{|l|}{7 day $(n=142)$} & \multicolumn{2}{|l|}{$\begin{array}{l}14 \text { day } \\
(n=83)\end{array}$} & \multicolumn{2}{|l|}{30 day $(n=46)$} & \multicolumn{2}{|l|}{7 day $(n=158)$} & \multicolumn{2}{|c|}{14 day $(n=116)$} & $30 d_{i}$ \\
\hline & Intervention & Control & Intervention & & Intervention & $\begin{array}{l}\text { Control } \\
n=38\end{array}$ & Intervention & & & & Inter \\
\hline & $n=50$ & $n=92$ & $n=14$ & $n=69$ & $n=8$ & & $n=50$ & $n=108$ & $n=34$ & $n=82$ & $n=21$ \\
\hline Cured & $36(72.0)$ & $23(25)$ & $6(42.9)$ & $31(44.9)$ & $4(50)$ & 13(34.2) & $16(32.0)$ & $26(24.1)$ & 13(38.2) & 17(20.7) & $15(7$ \\
\hline Failure & $14(28.0)$ & $69(75.0)$ & $8(57.1)$ & $38(55.1)$ & $4(50)$ & $25(65.8)$ & $34(68.0)$ & $82(75.9)$ & $21(61.8)$ & 65(79.3) & $6(28$ \\
\hline
\end{tabular}

\section{Discussion}

The use of insecticides with different formulations of lotions and shampoos is the most common method of controlling head lice and treatment of pediculosis. Sometimes, pediculicides are not effective and in some cases there is a possibility of recurrence. One of the possible causes of failure in treatment is the lack of awareness and proper use of pediculicides. Based on the results of the present study, the educational intervention showed a significant difference in the test group, but in the control group, this difference was not significant. In other words, teaching the way of using pediculicides properly and health tips were effective in treating and reducing recurrence. Several studies have been conducted in the treatment of head lice infestation [18-19]. Most studies have compared different treatments [19-21], and several studies have been conducted on the effectiveness of training programs on preventing pediculosis capitis [22-23]. No study was found to investigate the effect of training on the efficacy of pediculicides in the treatment of head lice. In a study conducted by Zareban, the health education program had a positive effect on reducing head lice infestation, and after educational intervention, the rate of infestation in the experimental group decreased by $17.6 \% \%$, but it did not difference in the control group [24]. In the study conducted by Chegini (2017), mothers received group discussion on the preventive behaviors of pediculosis and it led to a reduction in the incidence of pediculosis in their daughters [23]. However, in the study conducted by Eftekhari (2017), educational intervention is effective in promoting preventive behaviors against pediculosis on female elementary school students [22]. In general, the results of research confirmed the effectiveness of education in reducing the recurrence of head lice infestation in the study subjects. People knowledge of the way of properly use of pediculicides can significantly reduce the rate of head lice infestation. This issue should be considered by health care providers.

\section{Abbreviations}

GEE, Generalized Estimating Equation; PSM, Propensity Score Matching; SMD, Standardized Mean Difference .

\section{Declarations}

\section{Acknowledgements}

The authors are grateful to all colleagues at the University of Medical Sciences and staff at the health centers in the all counties in Ardabil Province.

\section{Authors' contributions}

EMA, concept design, synthesis and interpretation of data, drafting and revision of manuscript. AS ,ZT, data extraction, appraisal and synthesis, drafting of manuscript. MA,AH, literature search, drafting of manuscript. SHA, data extraction and synthesis, drafting of manuscript. All authors reviewed and approved the final manuscript.

\section{Funding}

This study was funded Ardabil University of Medical Sciences (ARUMS), Project Number: 237.

\section{Availability of data and materials}

All data generated or analyzed during this study are included in this published article.

\section{Ethics approval and consent to participate}

This article was approved by the Ethical Committee of Ardabil University of Medical Sciences, Iran (Code of ethics: IR.ARUMS. REC.1397.170).

\section{Consent for publication}

Not applicable.

\section{Competing interests}

The authors declare no competing interests.

\section{Author details}


${ }^{1}$ Department of Public Health, School of Public Health, Ardabil University of Medical Sciences, Ardabil, Iran,

${ }^{2}$ Department of Public Health, Faculty of Health, Qom University of Medical Sciences, Qom, Iran,

${ }^{3}$ Department of Family and Community Medicine, School of Medicine, Qom University of Medical Sciences, Qom, Iran,

${ }^{4}$ Department of Operating Room, School of Allied Medical Sciences, Qom University of Medical Sciences, Qom, Iran,

${ }^{5}$ Department of Medical Entomology , School of Public Health, Tehran University of Medical Sciences, Tehran, Iran,

\section{References}

1. BONILLA, D. L., DURDEN, L. A., EREMEEVA, M. E. \& DASCH, G. A. 2013. The biology and taxonomy of head and body lice-implications for louse-borne disease prevention. PLOS pathogens, 9.

2. SHAYEGHI, M. \& PAKSA, A. 2010. Epidemiology of head lice infestation in primary school pupils, in khajeh city, East azerbaijan province, iran. Iranian journal of arthropod-borne diseases, 4, 42.

3. MOOSAZADEH, M., AFSHARI, M., KEIANIAN, H., NEZAMMAHALLEH, A. \& ENAYATI, A. A. 2015. Prevalence of head lice infestation and its associated factors among primary school students in Iran: a systematic review and meta-analysis. Osong public health and research perspectives, $6,346-356$.

4. ASHCROFT, R., SEKO, Y., CHAN, L. F., DERE, J., KIM, J. \& MCKENZIE, K. 2015. The mental health impact of bed bug infestations: a scoping review. International journal of public health, $60,827-837$.

5. SANGARE, A. K., DOUMBO, O. K. \& RAOULT, D. 2016. Management and treatment of human lice. BioMed research international, 2016.

6. KARAMI JOOSHIN, M., IZANLOO, H., SAGHAFIPOUR, A. \& GHAFOORI, Y. 2019. Study on efficacy of $1 \%$ permethrin shampoo and $4 \%$ dimethicone lotion as pediculicide products used in Iran: a clinical trial. Tehran University Medical Journal TUMS Publications, 77, 41-46.

7. FLINDERS, D. C. \& DE SCHWEINITZ, P. 2004. Pediculosis and scabies. American family physician, 69, 341-348.

8. FIROOZFAR, F., MOOSA-KAZEMI, S. H., BAHRAMI, A., YUSUF, M. A., SAGHAFIPOUR, A., ARMOON, Z., RAJABZADEH, R. \& HOSSEINI, S. H. 2019. Head lice infestation (Pediculus humanus capitis) prevalence and its associated factors, among the kormanj tribes in North Khorasan Province. Shiraz E Medical Journal, 20.

9. SAGHAFIPOUR, A., NEJATI, J., ZAHRAEI RAMAZANI, A., VATANDOOST, H., MOZAFFARI, E. \& REZAEI, F. 2017. Prevalence and risk factors associated with head louse (Pediculus humanus capitis) in Central Iran. International Journal of Pediatrics, 5, 5245-5254.

10. ADHAM, D., MORADI-ASL, E., ABAZARI, M., SAGHAFIPOUR, A. \& ALIZADEH, P. Forecasting head lice (Pediculidae: Pediculus humanus capitis) infestation incidence hotspots based on spatial correlation analysis in Northwest Iran, Veterinary World, 13 (1): 40-46. 2020.

11. ROSENBAUM, P. R. 2010. Design of observational studies, New York, NY, Springer.

12. ROSENBAUM, P. R. \& RUBIN, D. B. 1983. The central role of the propensity score in observational studies for causal effects. Biometrika, $70,41-55$.

13. KURTH, T., WALKER, A. M., GLYNN, R. J., CHAN, K. A., GAZIANO, J. M., BERGER, K. \& ROBINS, J. M. 2005. Results of Multivariable Logistic Regression, Propensity Matching, Propensity Adjustment, and Propensity-based Weighting under Conditions of Nonuniform Effect. American Journal of Epidemiology, 163, 262-270.

14. ZHANG, Z., KIM, H. J., LONJON, G., ZHU, Y. \& WRITTEN ON BEHALF OF, A. M. E. B.-D. C. T. C. G. 2019. Balance diagnostics after propensity score matching. Annals of translational medicine, 7, 16-16.

15. STUART, E. A., LEE, B. K. \& LEACY, F. P. 2013. Prognostic score-based balance measures can be a useful diagnostic for propensity score methods in comparative effectiveness research. Journal of Clinical Epidemiology, 66, S84-S90.e1.

16. AUSTIN, P. C. 2011. An Introduction to Propensity Score Methods for Reducing the Effects of Confounding in Observational Studies. Multivariate Behavioral Research, 46, 399-424.

17. HOMISH, G. G., EDWARDS, E. P., EIDEN, R. D. \& LEONARD, K. E. 2010. Analyzing family data: A GEE approach for substance use researchers. Addictive Behaviors, 35, 558-563.

18. HEUKELBACH, J., WOLF, D., CLARK, J. M., DAUTEL, H. \& ROESCHMANN, K. 2019. High efficacy of a dimeticone-based pediculicide following a brief application: in vitro assays and randomized controlled investigator-blinded clinical trial. BMC dermatology, 19, 14.

19. KALARI, H., SOLTANI, A., AZIZI, K., FARAMARZI, H. \& MOEMENBELLAH-FARD, M. D. 2019. Comparative efficacy of three pediculicides to treat head lice infestation in primary school girls: a randomised controlled assessor blind trial in rural Iran. BMC dermatology, 19, 13.

20. MOEMENBELLAH-FARD, M. D., NASIRI, Z., AZIZI, K. \& FAKOORZIBA, M. R. 2016. Head lice treatment with two interventions: pediculosis capitis profile in female schoolchildren of a rural setting in the south of Iran. Annals of Tropical Medicine and Public Health, 9, 245.

21. BURGESS, I. F., BRUNTON, E. R. \& BURGESS, N. A. 2013. Single application of $4 \%$ dimeticone liquid gel versus two applications of $1 \%$ permethrin creme rinse for treatment of head louse infestation: a randomised controlled trial. BMC dermatology, 13, 5.

22. PEYMAN, N. 2018. Effect of Educational Intervention Based on Protection Motivation Theory on Promoting Pediculosis Preventive Behaviors among Elementary School Girls in Neyshabur. J Educ Community Health, 5, 1-7.

23. CHEGINI, P. G., ANOOSHEH, M. \& KAZEMNEJAD, A. 2017. The effectiveness of educating mothers on preventive behaviors of pediculosis on morbidity rate of their daughters. Payesh (Health Monitor), 16, 785-795. 
24. ZAREBAN, I., ABBASZADEH, M., MOODI, M., MEHRJOO FARD, H. \& GHAFFARI, H. 2006. Evaluating a health-education program in order to reduce infection to Pediculus Humanus Capitis among female elementary students. Journal of Birjand University of Medical Sciences, 13, 9-15.

\section{Figures}

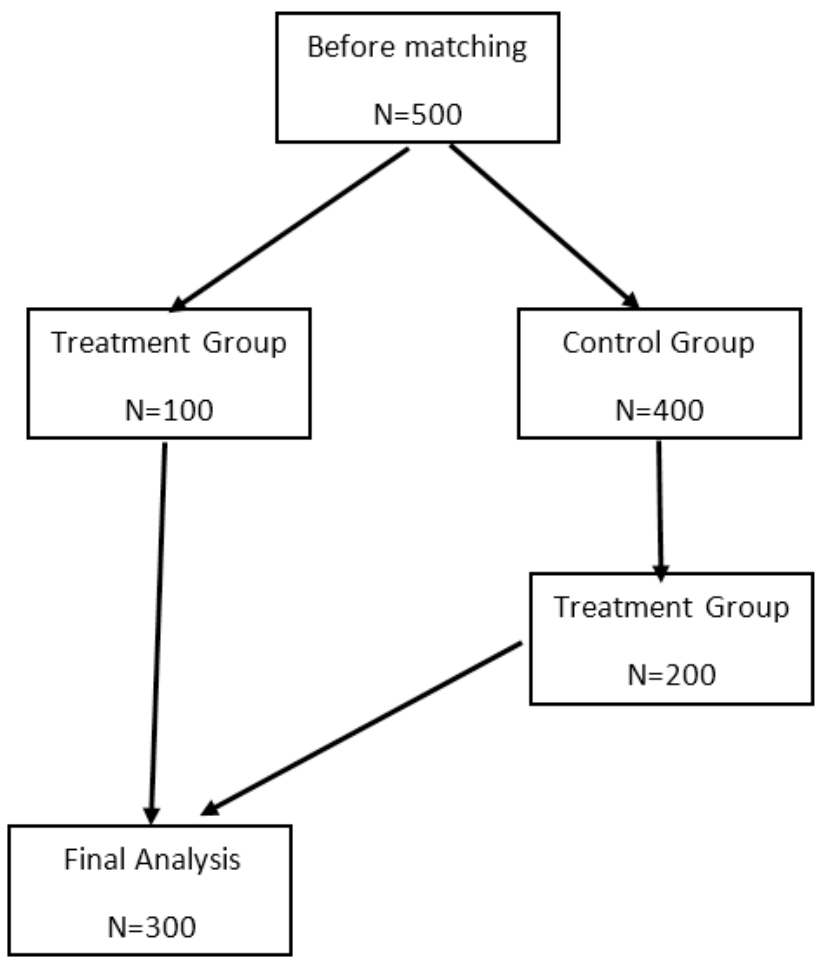

Figure 1

Study Follow Diagram 